\title{
In Vitro Antimicrobial, Antioxidant Activities and Phytochemical Analysis of Canarium patentinervium Miq. from Malaysia
}

\author{
R. Mogana, ${ }^{1}$ Khoo Teng-Jin, ${ }^{1}$ and C. Wiart ${ }^{2}$ \\ ${ }^{1}$ School of Pharmacy, Faculty of Science, University of Nottingham, Malaysia Campus, JlnBroga, Semenyih, 43500 Selangor, Malaysia \\ ${ }^{2}$ School of Biomedical Science, Faculty of Science, University of Nottingham, Malaysia Campus, JlnBroga, Semenyih, \\ 43500 Selangor, Malaysia
}

Correspondence should be addressed to R. Mogana, khyx1msa@nottingham.edu.my

Received 3 March 2011; Revised 7 April 2011; Accepted 2 May 2011

Academic Editor: Goetz Laible

Copyright (c) 2011 R. Mogana et al. This is an open access article distributed under the Creative Commons Attribution License, which permits unrestricted use, distribution, and reproduction in any medium, provided the original work is properly cited.

\begin{abstract}
Six different extracts of Canarium patentinervium Miq. (Burseraceae) leaves and barks were screened for their phytochemical composition, and antimicrobial and free radical scavenging activities. Among the different extracts tested, the ethanol extract of leaves showed significant antimicrobial and radical scavenging activities. The most susceptible micro-organisms were found to be Gram-positive bacteria (Staphylococcus aureus, methicillin-resistant Staphylococcus aureus or MRSA) and Gram-negative bacteria (Pseudomonas aeruginosa). Phytochemical analysis of the extracts revealed that the antimicrobial and the radical scavenging activities are mainly due to the presence of tannins and flavonoids. The results obtained suggest that Canarium patentinervium Miq. could be exploited in the management of various infectious diseases.
\end{abstract}

\section{Introduction}

Infectious diseases remain the leading cause of death worldwide, and bacteria have become more resistant to conventional antibiotic in recent years [1]. The number of resistant pathogenic bacteria grows at an alarming rate worldwide, and the search for novel antimicrobial agents from medicinal plants to combat such pathogens has become crucial for avoiding the emergence of untreatable bacterial infections $[2,3]$.

Bacterial infections have been known to generate extensive formation of free radicals [4]. The role of free radicals and active oxygen is becoming increasingly recognized in the pathogenesis of the many human diseases, including cancer, neurodegenerative diseases, ageing, and atherosclerosis [5]. Free radicals can also cause lipid peroxidation in foods that leads to their deterioration. Synthetic antioxidants, such as butylated hydroxyanisole (BHA) and butylated hydroxytoluene (BHT), are suspected of carcinogenicity and of hormonal perturbation $[6,7]$. Therefore, the search for natural antioxidants has been greatly intensified in recent years.

In continuation of our earlier studies on the pharmacological properties of Malaysian plants [8], this study was undertaken to screen the phytochemical composition, antimicrobial and radical scavenging activities of different extracts of Canarium patentinervium Miq. Canarium patentinervium Miq. belongs to the family of Burseraceae best known for producing resins of economic, medicinal, and cultural values such as frankincense, myrrh, and copal [9]. This family consist of 18 genera and 700 species of trees [10]. In the Asia-Pacific region, about 20 species of Burseraceae are used to heal wounds and to treat skin infections [11]. One such species is Canarium patentinervium Miq. which has been used to heal wounds in Malay traditional medicine. Furthermore, no pharmacological and phytochemical studies have been reported on this species to date.

\section{Materials and Methods}

2.1. Plant Material. The leaves and barks of Canarium patentinervium Miq. were collected from one individual tree in April 2010 from Bukit Putih, Selangor, Malaysia $\left(3^{\circ} 5^{\prime} 24^{\prime \prime} \mathrm{N}\right.$ $101^{\circ} 46^{\prime} 0^{\prime \prime}$ E). The plant was identified by Mr. Kamaruddin (Forest Research Institute of Malaysia). A herbarium sample (PID 251210-12) has been deposited in the Forest Research Institute of Malaysia. The leaves and barks were air dried and grinded into small particles using an industrial grinder. 
2.2. Chemical and Reagents. 1,1-diphenyl-2-picryhydrazyl (DPPH) was purchased from Aldrich. Sodium chloride, ascorbic acid, ferric chloride, and glacial acetic acid were purchased from Systerm. Mueller Hilton agar (Hi media, India), tryptic soy broth, and tryptic soy agar were purchased from (Bacto), hexane and chloroform were purchased from Friendemann Schmidt Chemicals. Methanol and ethanol 95\% was purchased from Kollin Chemicals. Bovine gelatin powder and DMSO were from R\&M Marketing, Essex UK. Antibiotics streptomycin and ampicillin were purchased from Sigma Aldrich, Germany and Amresco, Ohio, USA respectively.

2.3. Extraction. Dried and grinded sample of leaves $(2.8 \mathrm{~kg})$ and barks $(1.7 \mathrm{~kg})$ were soaked in hexane with the ratio of $1: 3$ parts of sample to solvent for $2 \mathrm{~h}$ in a $60^{\circ} \mathrm{C}$ water bath, then filtered and concentrated with a rotary evaporator (Buchi, R-200 Switzerland). This was repeated 3 times. Thereafter, the leaves and barks were left to air dry completely for 3 days before repeating the whole process with chloroform, and then ethanol, respectively. The yield for the hexane, chloroform and ethanol extract of leaves were $1.25 \%$, $1.11 \%$, and $6.45 \%$, respectively. The yield for the hexane, chloroform, and ethanol extract of barks were $1.04 \%, 0.4 \%$, and $2.61 \%$, respectivetly. Crude extracts were kept at $-20^{\circ} \mathrm{C}$ until further use.

2.4. Preliminary Phytochemical Analysis. Qualitative phytochemical analysis of the crude extract was determined as follows $[12,13]$.

Alkaloids. $200 \mathrm{mg}$ of the extract was dissolved in $10 \mathrm{~mL}$ of methanol and heated on a boiling water bath with $2 \mathrm{~N} \mathrm{HCl}$ $(5 \mathrm{~mL})$. After cooling, the mixture was filtered and the filtrate was divided into two equal portions. One portion was treated with a few drops of Mayer's reagent and the other with equal amounts of Wagner's reagent. The samples were then observed for the presence of turbidity or precipitation. A $(+)$ score was recorded if the reagent produced only a slight opaqueness; a $(++)$ score was recorded if a definite turbidity, but no flocculation was observed, and a $(+++)$ score was recorded if a definite heavy precipitate or flocculation was produced.

Mayer's reagent. Solution I: $1.36 \mathrm{~g} \mathrm{HgCl}_{2}$ was dissolved in $60 \mathrm{~mL}$ water. Solution II: $5 \mathrm{~g}$ KI was dissolved in $10 \mathrm{~mL}$ water. Both solutions are combined and diluted with water to $100 \mathrm{~mL}$. If alkaloids are present a white to yellowish precipitate will appear.

Wagner reagent. $1.27 \mathrm{~g} \mathrm{I}_{2}$ (sublimed) and $2 \mathrm{~g} \mathrm{KI}$ was dissolved in $20 \mathrm{~mL}$ water, and water is made up to $100 \mathrm{~mL}$. A brown precipitate indicates the presence of alkaloids.

Flavonoids. $40 \mathrm{mg}$ plant material was dissolved in $2 \mathrm{~mL}$ ethanol and filtered. The filtrate was treated with a few drops of concentrated $\mathrm{HCl}$ and magnesium turnings $(0.5 \mathrm{~g})$. The presence of flavonoids was indicative if pink or magenta-red color developed within $3 \mathrm{~min}$.
TABle 1: Preliminary phytochemical analysis of the crude extract of Canarium patentinervium Miq.

\begin{tabular}{lccccc}
\hline Sample & Alkaloids & Flavonoids & Saponins & Tannins & Steroids \\
\hline LH & - & - & - & - & - \\
LC & - & - & - & - & - \\
LE & - & +++ & - & +++ & +++ \\
BH & - & - & - & - & +++ \\
BC & - & - & - & - & ++ \\
BE & - & +++ & - & +++ & +++ \\
\hline
\end{tabular}

LH: leaf hexane extract, LC: leaf chloroform extract, LE: leaf ethanol extract, $\mathrm{BH}$ : bark hexane extract, BC: bark chloroform extract, BE: bark ethanol extract, and -: negative, + : trace, ++ : positive, and +++ : strongly positive.

Saponins. About $2.5 \mathrm{~g}$ of the plant material was extracted with boiling water. After cooling, the extract was shaken vigorously to froth and was then allowed to stand for 15$20 \mathrm{~min}$ and classified for saponin content as follows: (no froth = negative; froth less than $1 \mathrm{~cm}=$ weakly positive; froth $1.2 \mathrm{~cm}$ high = positive; and froth greater than $2 \mathrm{~cm}$ high $=$ strongly positive).

Tannins. About $10 \mathrm{mg}$ of extract was dissolved in $6 \mathrm{~mL}$ of hot distilled water and filtered. The solution is divided in three test tubes. To the first $0.9 \%$ sodium chloride solution was added, to the second $0.9 \%$ sodium chloride and $1 \%$ gelatine solution was added, and to the third ferric chloride $\left(\mathrm{FeCl}_{3}\right)$ was added. Formation of a precipitate in the second treatment suggests the presence of tannins, and a positive response after addition of $\mathrm{FeCl}_{3}$ to the third portion which will result in a characteristic blue, blue-black, green, or bluegreen color supports this inference.

Sterols (Salkowski Reaction). $40 \mathrm{mg}$ of extract was dissolved in $2 \mathrm{~mL}$ of chloroform and filtered. The filtrate was then added to $1 \mathrm{~mL}$ of concentrated $\mathrm{H}_{2} \mathrm{SO}_{4}$. The presence of sterols was indicated by the 2 phase formation with a red color in the chloroform phase.

\subsection{Antimicrobial Assay}

2.5.1. Bacterial Strain. In vitro antimicrobial activity was examined for hexane, chloroform, and ethanol extracts of Canarium patentinervium Miq. The following bacterial strains were employed in the screening: Gram-positive bacteria such as Staphylococcus aureus (ATCC 11632), Bacillus cereus (ATCC 10876), methicillin-resistant Staphylococcus aureus (ATCC 43300), and Gram-negative bacteria such as Escherichia coli (ATCC 10536) and Pseudomonas aeruginosa (ATCC 10145).

2.5.2. Disc Diffusion Assay. The tests were performed using Mueller Hilton medium for bacterial strains using disc diffusion method following the National Committee for Clinical Laboratory Standards methods [14, 15]. The sterile petri dishes containing solid and sterile Mueller Hilton agar medium (HiMedia) were used. Sterile paper disc $(6 \mathrm{~mm})$ 
TABle 2: Antibacterial activity of Canarium patentinervium Miq. (1 mg/disc) versus ampicillin and streptomycin (1 $\mathrm{gg} /$ disc) against 5 bacterial species tested by disc diffusion assay.

\begin{tabular}{|c|c|c|c|c|c|}
\hline \multirow{2}{*}{ Plant extract } & \multicolumn{5}{|c|}{ Zone of inhibition $(\mathrm{mm})^{\mathrm{a}}$} \\
\hline & S. aureus & B. cereus & MRSA & E. coli & P. aeruginosa \\
\hline LH & - & - & - & - & - \\
\hline $\mathrm{LC}$ & - & - & - & - & - \\
\hline LE & $12.0 \pm 0.2$ & $10.0 \pm 0.4$ & $12.0 \pm 0.3$ & - & $11.0 \pm-0.3$ \\
\hline $\mathrm{BH}$ & $11.0 \pm 0.3$ & $9.0 \pm 0.3$ & $12.0 \pm 0.5$ & - & $12.0 \pm 0.5$ \\
\hline $\mathrm{BC}$ & $7.0 \pm 0.3$ & - & - & - & - \\
\hline $\mathrm{BE}$ & $9.0 \pm 0.6$ & $9.0 \pm 0.0$ & - & - & - \\
\hline Ampicilin ${ }^{\mathrm{b}}$ & $10.0 \pm 0.7$ & $8.0 \pm 0.0$ & - & $7.0 \pm 0.0$ & - \\
\hline Streptomycin ${ }^{\mathrm{b}}$ & $7.0 \pm 0.1$ & $11.0 \pm 0.5$ & $7.0 \pm 0.1$ & - & - \\
\hline
\end{tabular}

LH: leaf hexane extract, LC: leaf chloroform extract, LE: leaf ethanol extract, BH: bark hexane extract, BC: bark chloroform extract, BE: bark ethanol extract, ${ }^{\mathrm{a}}$ : inhibition zones are the mean including disc $(6 \mathrm{~mm})$, ${ }^{\text {b }}$ : ampicillin and streptomycin at $100 \mu \mathrm{g} / \mathrm{mL}=1 \mu \mathrm{g} / \mathrm{disc}$, and —: no activity noted, that is, inhibition zone of $6 \mathrm{~mm}$.

was saturated with $10 \mu \mathrm{L}$ of sample at a concentration of $1 \mathrm{mg} /$ disc and allowed to dry for $24 \mathrm{~h}$. The bacterial suspension which was prepared from a $24 \mathrm{~h}$ culture using tryptic soy broth (Bacto) was adjusted to an inoculation of $1 \times 10^{8} \mathrm{cfu} / \mathrm{mL}$. Turbidity at $625 \mathrm{~nm}$ was adjusted with $0.9 \%$ sterile normal saline. The dried surface of the Mueller Hilton agar plate was streaked, and dried discs were placed per petri dish in triplicates. The plates were then incubated at $35^{\circ} \mathrm{C}$ for $24 \mathrm{~h}$. Positive and negative controls were performed for every test. For each plate negative controls were maintained where pure solvents were used instead of extract. Positive control was ampicillin and streptomycin. Microbial growth was determined by measuring the diameter of the zone of inhibition with a caliper. The inhibition zones would thus include disc size of $6 \mathrm{~mm}$. The experiment was done three times, and the mean values are presented.

2.6. DPPH Assay. The DPPH assay, as described by JuanBadaturuge et al. [16], was employed to determine the radical scavenging activity of the plant extracts. Aliquots of plant extract dissolved in dimethyl sulfoxide (DMSO, $\mathrm{R} \& \mathrm{M}$ ) were plated out in triplicate in a 96-well microtiter plate. The $0.1 \mathrm{mM}$ DPPH solution (Aldrich) was added to alternating columns of the test samples and methanol for control of test samples, in the remaining columns. The plate was shaken for $2 \mathrm{~min}$ and incubated for $30 \mathrm{~min}$ in the dark. The percentage decolourisation was obtained spectrophotometrically at $550 \mathrm{~nm}$ using the Thermo Scientific Varioskan Flash microtiter plate reader, linked to a computer equipped with (SkanIt Software 2.4.3). Percentage decolourisation was plotted against the concentration of the sample, and the $\mathrm{EC}_{50}$ values were determined using Prism 5.00 software. Vitamin C (1-ascorbic acid) was used as positive control. At least, three independent tests were performed for each sample. The DPPH absorbance decreases with an increase in DPPH radical scavenging activity. This activity is given as percent DPPH radical scavenging, which is calculated with the equation: $\mathrm{DPPH}$ radical scavenging activity $(\%)=$ $\left[\left(\mathrm{Abs}_{\text {control }}-\mathrm{Abs}_{\text {sample }}\right) /\left(\mathrm{Abs}_{\text {control }}\right)\right] \times 100$ where $\mathrm{Abs}_{\text {control }}$ is the absorbance of DPPH radical + methanol and $\mathrm{Abs}_{\text {sample }}$ is the absorbance of DPPH radical + sample extract/standard.
TABLE 3: DPPH radical scavenging activity at $10 \mu \mathrm{g} / \mathrm{mL}$ of extract.

\begin{tabular}{lc}
\hline Extracts & \% DPPH radical scavenging \\
\hline LH & $38.90 \pm 0.02$ \\
LC & $3.00 \pm 0.01$ \\
LE & $65.80 \pm 0.01$ \\
BH & $5.00 \pm 0.01$ \\
BC & $8.00 \pm 0.02$ \\
BE & $77.80 \pm 0.01$ \\
AA & $97.90 \pm 0.00$ \\
\hline
\end{tabular}

LH: leaf hexane extract, LC: leaf chloroform extract, LE: leaf ethanol extract, BH: bark hexane extract, BC: bark chloroform extract, BE: bark ethanol extract, and AA: ascorbic acid

2.7. Statistical Analysis. Concentration-response curves were calculated using the Prism software package 5.00 for Windows, GraphPad Software, San Diego, Calif, USA, http://www.graphpad.com/ (GraphPad, San Diego, Calif, USA) and data were reported as mean and SD values obtained from a minimum of three determinations. Nonlinear best fit was plotted with SD and 95\% confidence interval.

\section{Results and Discussion}

3.1. Preliminary Phytochemical Analysis. Phytochemical analysis of Canarium patentinervium Miq. (Table 1) revealed presence of tannins and flavonoids in the ethanol extract of leaves and barks. Triterpenoids can be divided into at least four groups of compounds, namely, true triterpenes, steroids, saponins, and cardiac glycosides [17]. Steroids were detected in the ethanol extract of leaves and all tested bark extracts.

3.2. Antimicrobial Activity. The antibacterial activity of six extracts of Canarium patentinervium Miq. was evaluated (Table 2). The extracts were screened for activity against Gram-positive bacteria (Staphylococcus aureus, MRSA, and Bacillus cereus) and Gram-negative bacteria (Escherichia coli and Pseudomonas aeruginosa) by agar disc diffusion method. The ethanol extract of leaves and the hexane extract of 


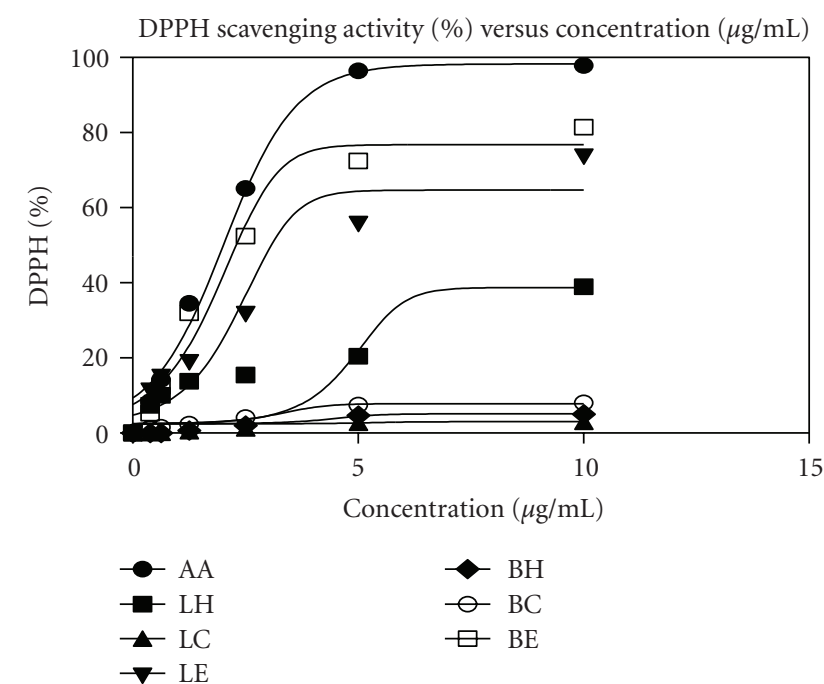

FIGURE 1: DPPH scavenging activity (\%) of Canarium patentinervium Miq. LH: leaf hexane extract, LC: leaf chloroform extract, LE: leaf ethanol extract $\mathrm{BH}$ : bark hexane extract, BC: bark chloroform extract, BE: bark ethanol extract, and AA: ascorbic acid.

bark displayed remarkable antibacterial activity against both Gram-positive bacteria and Gram-negative bacteria. The best sensitivity to the ethanol extract of the leaves at $1 \mathrm{mg} / \mathrm{disc}$ was, respectively, obtained against Staphylococcus aureus (12 $\mathrm{mm})$, MRSA (12 mm), Bacillus cereus $(10 \mathrm{~mm})$, and Pseudomonas aeruginosa $(11 \mathrm{~mm})$. The chloroform extract of leaves and barks and the hexane extract of leaves showed no activity.

3.3. Antioxidant Activity. DPPH is a stable free radical which accepts an electron or hydrogen radical to become a stable diamagnetic molecule, which is widely used to investigate radical-scavenging activity. In DPPH radicalscavenging assay, antioxidants react with DPPH, and convert it to yellow coloured $\alpha, \alpha$-diphenyl- $\beta$-picryl hydrazine. The degree of discolouration indicates the radical-scavenging potential of the antioxidant activities [18]. In this test, the ethanol extract of leaves and barks exhibited profound antioxidant activities (Figure 1). The antioxidant activities were highest for ethanol extract of barks $(77.80 \pm 0.01 \%)$ followed by the ethanol extract of leaves $(65.80 \pm 0.01 \%)$, the hexane extract of leaves $(38.90 \pm 0.02 \%)$, the chloroform extract of barks $(8.00 \pm 0.02 \%)$, the hexane extract of barks $(5.00 \pm 0.01 \%)$, and the chloroform extract of leaves $(3.00 \pm$ $0.01 \%)$ against standard ascorbic acid which was $(97.90 \pm$ $0.00 \%$ ) at the dose of $10 \mu \mathrm{g} / \mathrm{mL}$ (Table 3$)$. The $\mathrm{EC}_{50}(\mu \mathrm{g} / \mathrm{mL})$ for the ethanol extract of barks $(2.33 \mu \mathrm{g} / \mathrm{mL})$ and leaves $(2.93 \mu \mathrm{g} / \mathrm{mL})$ were as good as ascorbic acid $(1.88 \mu \mathrm{g} / \mathrm{mL})$.

\section{Conclusion}

Plant substances continue to serve as a wellspring of drugs for the world population, and severalplant-based drugs are in extensive clinical use [19]. In the present study, antibacterial screening of six extracts of Canarium patentinervium Miq. showed varying degrees of antibacterial activity against human pathogenic bacteria such as Staphylococcus aureus, MRSA, Bacillus cereus, and Pseudomonas aeruginosa cultured in vitro. Out of six extracts, the ethanol extract of leaves and hexane extract of barks exhibited significant antibacterial activity against both Gram-positive and Gram-negative bacteria. This is of special interest since most Gram-negative bacteria are more resistant to plant extracts [20].

The antioxidant activity reflected by the DPPH radical scavenging assay was clearly observed in the ethanol extracts of barks and leaves. Results from our phytochemical analysis revealed that the ethanol extract of leaves and barks of Canarium patentinervium Miq. accumulate substantial amounts of flavonoids and tannins which could be well correlated with the activities measured. We shall conduct further work to isolate the antioxidant and antibacterial constituents of the plant and evaluate their minimum inhibitory concentration (MIC).

\section{Acknowledgment}

The authors are grateful to Radha Krsna and Mr. Kamaruddin (FRIM) for plant identification.

\section{References}

[1] WHO, "Containing Antimicrobial Resistance," 1999.

[2] M. A. Pfaller, R. N. Jones, G. V. Doern, and K. Kugler, "Bacterial pathogens isolated from patients with bloodstream infection: frequencies of occurrence and antimicrobial susceptibility patterns from the SENTRY antimicrobial surveillance program (United States and Canada, 1997)," Antimicrobial Agents and Chemotherapy, vol. 42, no. 7, pp. 1762-1770, 1998.

[3] J. E. Bandow, H. Brötz, L. Leichert, H. Labischinski, and M. Hecker, "Proteomic approach to understanding antibiotic action," Antimicrobial Agents and Chemotherapy, vol. 47, no. 3, pp. 948-955, 2003.

[4] H. Maeda and T. Akaike, "Nitric oxide and oxygen radicals in infection, inflammation and cancer," Biochemistry (Moscow), vol. 63, no. 7, pp. 854-865, 1998.

[5] R. J. Perry, P. Watson, and J. R. Hodges, "The nature and staging of attention dysfunction in early (minimal and mild) Alzheimer's disease: relationship to episodic and semantic memory impairment," Neuropsychologia, vol. 38, no. 3, pp. 252-271, 2000.

[6] N. Ito, S. Fukushima, A. Hassegawa, M. Shibata, and T. Ogiso, "Carcinogenicity of butylated hydroxyanisole in F344 rats," Journal of the National Cancer Institute, vol. 70, no. 2, pp. 343352, 1983.

[7] C. P. Jayalakshmi and J. D. Sharma, "Effect of butylated hydroxyanisole (BHA) and butylated hydroxytoluene (BHT) on rat erythrocytes," Environmental Research, vol. 41, no. 1, pp. 235-238, 1986.

[8] C. Wiart, S. Mogana, S. Khalifah et al., "Antimicrobial screening of plants used for traditional medicine in the state of Perak, Peninsular Malaysia," Fitoterapia, vol. 75, no. 1, pp. 68-73, 2004.

[9] J. H. Langenheim, Plant Resins: Chemistry, Evolution, Ecology, and Ethnobotany, Timber Press, Portland, Ore, USA, 2003. 
[10] A. Weeks, D. C. Daly, and B. B. Simpson, "The phylogenetic history and biogeography of the frankincense and myrrh family (Burseraceae) based on nuclear and chloroplast sequence data," Molecular Phylogenetics and Evolution, vol. 35, no. 1, pp. 85-101, 2005.

[11] C. Wiart, Medicinal Plants of the Asia-Pacific: Drugs for the Future? World Scientific Publishing, British Library Cataloguing-in-Publication Data, River Edge, NJ, USA, 2006.

[12] M. Kamalinejad, F. Mojab, N. Ghaderi, and H. R. Vahidipour, "Phytochemical screening of some species of Iranian plants," Iranian Journal of Pharmaceutical Research, vol. 2, pp. 77-82, 2003.

[13] "Extraction of plant secondary metabolites," in Natural Products Isolation, Satyajit D. Sarker and Alexander I. Gray, Eds., pp. 339-342, 2nd edition, 2006.

[14] J. A. Kiehlbauch, G. E. Hannett, M. Salfinger, W. Archinal, C. Monserrat, and C. Carlyn, "Use of the National Committee for Clinical Laboratory Standards guidelines for disk diffusion susceptibility testing in New York state laboratories," Journal of Clinical Microbiology, vol. 38, no. 9, pp. 3341-3348, 2000.

[15] National Committee for Clinical Laboratory Standards, "Performance standards for antimicrobial susceptibility testing," in 8 th Informational Supplement, M100 S12. National Committee for Clinical Laboratory Standards, 2002.

[16] M. Juan-Badaturuge, S. Habtemariam, and M. J. K. Thomas, "Antioxidant compounds from a South Asian beverage and medicinal plant, Cassia auriculata," Food Chemistry, vol. 125, no. 1, pp. 221-225, 2011.

[17] J. B. Harborne, "The terpenoid," in Phytochemical Methods, p. 129, 1998.

[18] M. S. Blois, "Antioxidant determinations by the use of a stable free radical," Nature, vol. 181, no. 4617, pp. 1199-1200, 1958.

[19] S. S. Handa, Status of Medicinal and Aromatic Plants (MAPs) Utilization Globally Including Issues of Quality Control and Technologies forLarge Scale Production of Plant Based Products, United Nations Industrial Development Organization (UNIDO), 2007.

[20] A. C. Kudi, J. U. Umoh, L. O. Eduvie, and J. Gefu, "Screening of some Nigerian medicinal plants for antibacterial activity," Journal of Ethnopharmacology, vol. 67, no. 2, pp. 225-228, 1999. 

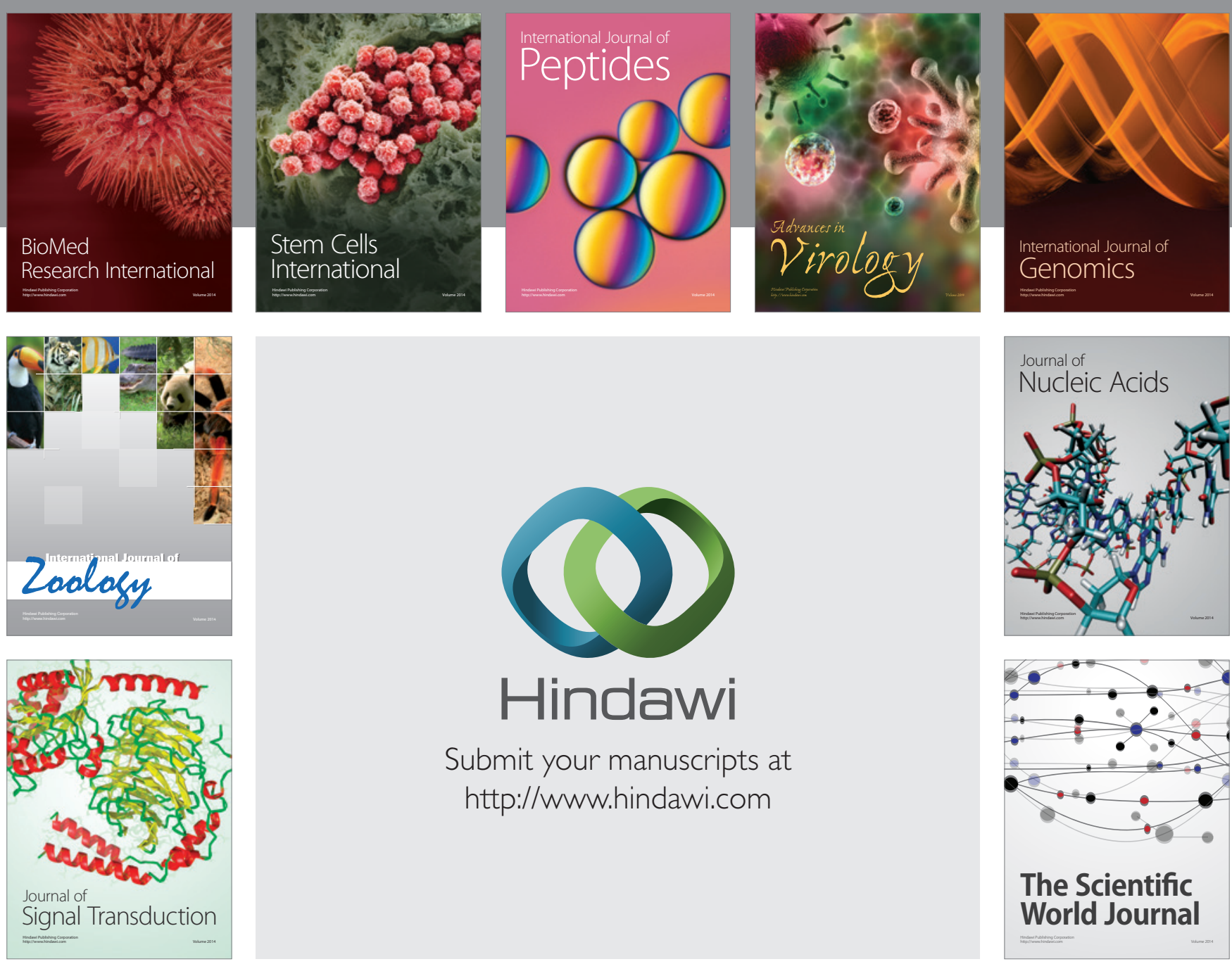

Submit your manuscripts at

http://www.hindawi.com
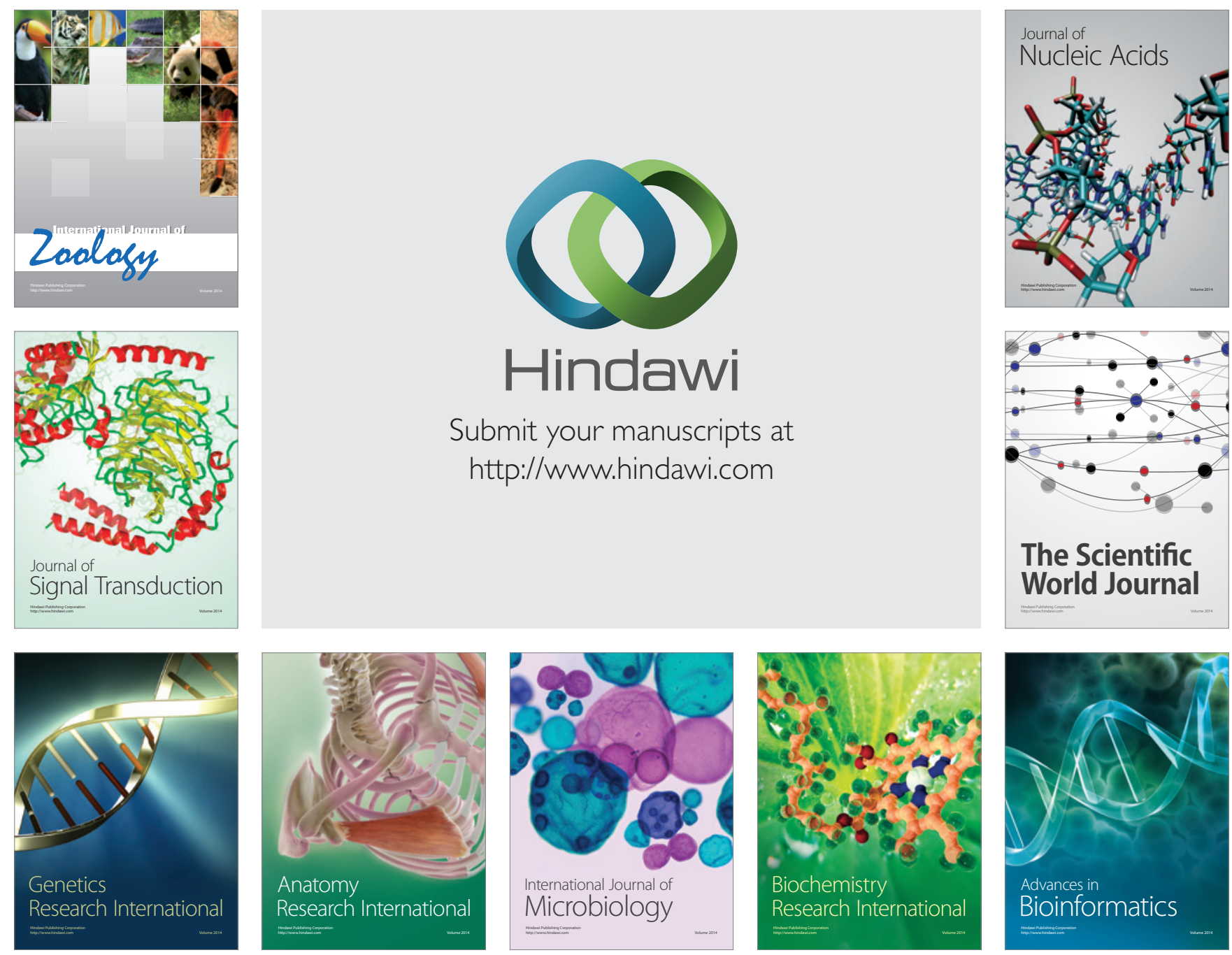

The Scientific World Journal
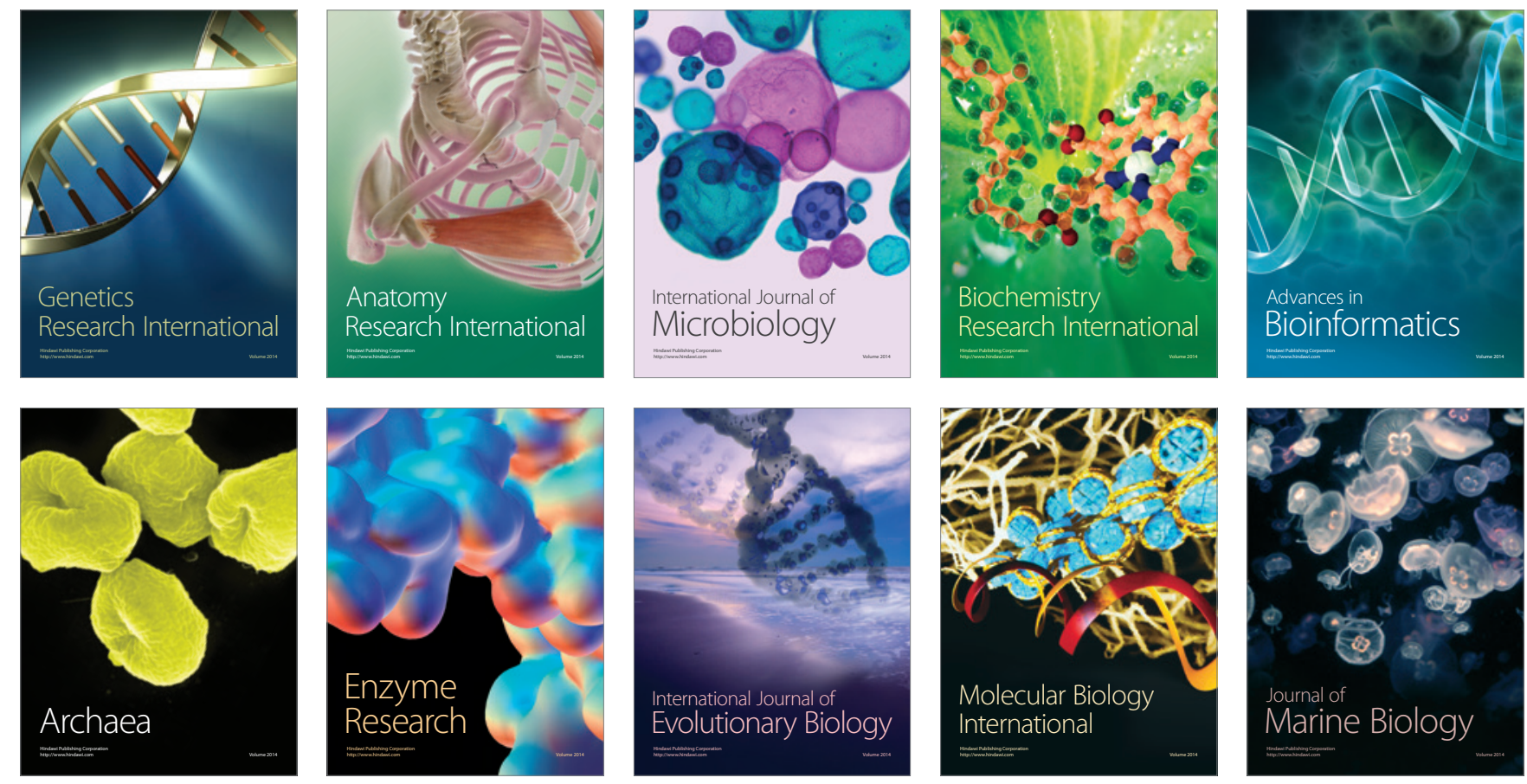